\title{
Use of Recycled Pulped Chromated Copper Arsenate-Treated Wood Fibre in Polymer Composites
}

\author{
Wouter Peerbooms ${ }^{1, *}$ (1) and Kim L. Pickering 2 (D) \\ 1 Department of Mechanical Engineering, Eindhoven University of Technology, \\ 5600MB Eindhoven, The Netherlands \\ 2 School of Engineering, The University of Waikato, Hamilton 3240, New Zealand; klp@waikato.ac.nz \\ * Correspondence: w.peerbooms@student.tue.nl
}

Received: 8 May 2018; Accepted: 5 June 2018; Published: 11 June 2018

\begin{abstract}
The goal of this study was to investigate if it is possible to recycle chromated copper arsenate (CCA)-treated wood for use in wood polymer composites. This was done by soda pulping wood chips of CCA-treated lumber in a laboratory-scale digester. Composites of 10-30 weight percentage of filler in polypropylene were produced with and without the addition of maleic anhydride grafted polypropylene (MAPP) as a coupling agent. These composites were produced using extrusion compounding and injection moulding. The mechanical properties were determined using tensile testing; the properties examined in this study are the ultimate tensile strength, Young's modulus and strain at break. The effect of the CCA-treated filler on the dimensional stability was investigated by comparing the moisture absorption with virgin wood-filled composites. It was found that ultimate tensile strength improves with increasing filler percentage for the compositions with MAPP. The Young's modulus increases with increasing filler percentage for all compositions, and failure strain decreases with increasing filler percentage for all compositions. Moisture absorption studies show that the moisture absorption decreases when MAPP is added to the composite, and a slight decrease in moisture uptake is observed for the CCA-treated wood composites with respect to the virgin wood composites.
\end{abstract}

Keywords: wood fibres; polypropylene; chromated copper arsenate (CCA)-treated wood; recycled

\section{Introduction}

Wood polymer composites (WPCs) are materials that have a polymer matrix that is reinforced with wood particles or fibres. These WPCs are increasingly used especially in the construction and automotive industry [1-3]. Extensive research has been done on the use and improvement of these natural fibre-reinforced polymers, summarized in a number of literature reviews [3-5]. These reviews conclude that there is much potential for WPCs; because of the low density, high specific mechanical properties, non-abrasiveness to machinery and renewability of the fibre source. However, there are some challenges such as adhesion of the fibre and matrix material, degradation of the wood at high processing temperatures and moisture absorption of the composites. These challenges can be tackled by several fibre-treatment methods prior to use in the composite and the addition of coupling agents to the composite $[6,7]$.

Extensive research has been conducted on WPCs filled with wood flour. Kuo et al. [8] investigated the mechanical properties of several combinations of matrix material, wood flour type and fibre treatment in injection moulded WPCs. They showed that the effect of wood flour on the properties of the matrix depends on the matrix material used and the composition of the filler and additives. Furthermore, they show that wood flour has a positive effect on the mechanical properties. The literature also discusses the incorporation of different wood fibres in a polypropylene 
(PP) matrix $[9,10]$. These authors conclude that the mechanical properties of the composite depend on the type of wood, the geometry of the fibres and the addition of a coupling agent. An aspect that is brought forward strongly is that the addition of maleic anhydride grafted polypropylene (MAPP) has a large positive effect on the adhesion between the fibres and the matrix, and therewith on the mechanical properties. Furthermore, Stark and Rowlands [11] compared the use of wood fibres and wood flour in a PP matrix. The wood fibre composite showed higher strength than the wood flour composite. This increase in strength is attributed to the higher aspect ratio of the wood fibres, which was 5-8-times higher than the aspect ratio of the wood flour. Another comparative study was conducted by Nygärd et al. [12], which discussed wood powder and pelletized wood fibres in extrusion-based composites with a PP matrix. In this study, it is observed that the length of wood fibres is strongly reduced by pelletizing, which results in a lower aspect ratio of the fibres in the composite. The pelletizing does, however, allow for a controlled feed of the wood into the compounding extruder. The main conclusion of this study is that the mechanical properties and the dispersion of filler are improved by the addition of a coupling agent.

The literature on the use of chromated copper arsenate (CCA)-treated wood in WPCs shows the potential of this filler material. Kamdem et al. [13] investigated if recycled CCA-treated wood could be used in recycled high-density polyethylene (HDPE). Composites filled with wood flour were compared to composites filled with virgin pine filler. The results show improved flexural strength and better resistance to fungal decay and UV-weathering, for the CCA-treated wood filler. These improvements were attributed to the presence of the CCA in the wood particles. Additionally, Tascioglu et al. [14] determined the biological performance, dimensional stability, mechanical and thermal properties of HDPE filled with CCA wood flour from recycled CCA-treated wood. The dimensional stability study showed that the water absorption and thickness swelling increase with the amount of filler used. The water absorption and thickness swelling decrease, however, due to the addition of a coupling agent and with the use of CCA-treated wood. The mechanical testing of the CCA-treated wood composite shows better tensile and flexural properties, but lower impact strength than the virgin wood composites. The biological performance tests show that the CCA-treated wood filler improves the durability of the composite with respect to non-treated wood filler.

The goal of this study is to investigate if it is possible to recycle chromated copper arsenate-treated wood for use in wood polymer composites. This was done by soda pulping wood chips of CCA-treated lumber in a laboratory-scale digester. Composites of 10-30 weight percentage of filler in polypropylene was produced with and without the addition of MAPP as a coupling agent. These composites were produced using extrusion compounding and injection moulding. The mechanical properties were determined using tensile testing; the properties examined in this study were the ultimate tensile strength (UTS), Young's modulus and strain at break. The effect of the CCA-treated filler on the dimensional stability was investigated by comparing the moisture absorption with virgin wood filled composites.

\section{Materials and Methods}

In order to investigate the use of CCA-treated wood in WPCs, several materials and methods were used, which will be described in this section.

\subsection{Materials}

The CCA-treated wood (Radiata pine treated to hazard class H3.2) that was used in this research was obtained as newly treated wood from a lumber supply store (Thomsons ITM, Hamilton, New Zealand). The virgin wood used was also Radiata pine and obtained from the same store. To be able to process the lumber, it was turned into chips using a wood chipper normally used for tree trimmings. The matrix material that was used is polypropylene (Moplen EP332L from TCL Hunt, Auckland, New Zealand), which has a melt flow index of $6.9 \mathrm{~g} / \mathrm{min}$ at $230{ }^{\circ} \mathrm{C}$ and a melting temperature of $170{ }^{\circ} \mathrm{C}$. The MAPP used as a coupling agent is AC 950P maleic anhydride modified 
polypropylene (Honeywell, Morris Plains, NJ, USA). The compositions produced are 0, 10, 20 and $30 \mathrm{wt} \%$ wood filler; without MAPP, with $10 \mathrm{wt} \%$ MAPP of the amount of wood and $4 \mathrm{wt} \%$ MAPP of the total weight.

\subsection{Wood Pulping}

The CCA-treated wood and the virgin wood were subjected to a soda pulping process. The size of the wood chips was reduced using an industrial granulator equipped with a grid of 8-mm circular holes. The chips were dried overnight at $80^{\circ} \mathrm{C}$ before pulping in a laboratory-scale digester. The wood chips were loaded into the digesting canisters with a solution of $20 \mathrm{wt} \% \mathrm{NaOH}$ (on wood), and a liquor to wood ratio of 7:1 was used. A ramp time of two hours was used to reach $160{ }^{\circ} \mathrm{C}$, and a holding time of two hours was maintained. The digester was rapidly cooled to approximately $30^{\circ} \mathrm{C}$. After this treatment, the resulting material was washed with water and dried overnight at $80{ }^{\circ} \mathrm{C}$. To produce pulp that is usable in WPC, the digesting procedure was applied twice to the same wood chips. $\mathrm{NaOH}$ was used as the pulping liquor because the CCA additives in the wood might produce volatile gases when exposed to a strongly oxidizing or reducing chemical solution, as is used in more common pulping methods.

\subsection{Compounding}

Compounding of the composites was done in a ThermoPrism TSE-16-TC co-rotating twin screw extruder (Thermo Fisher Scientific, Waltham, MA, USA). The five heating zones were set to 150, $170,170,170$ and $165^{\circ} \mathrm{C}$, from the feeding zone to the exit. The rotation speed of the screws was set to $165 \mathrm{RPM}$. The CCA-treated wood fibres and PP pellets were dried for at least $24 \mathrm{~h}$ at $80^{\circ} \mathrm{C}$ before compounding. The different components were mixed by hand before feeding into the extruder. The extrudate was cooled in air and granulated to a suitable size for injection moulding, using an industrial granulator.

\subsection{Injection Moulding}

Injection moulding was performed using a Dr. Boy 35A injection moulder (Dr. BOY GmbH \& Co. KG, Neustadt-Fernthal, Germany). The composites were dried overnight at $80^{\circ} \mathrm{C}$ before injection moulding. The heating profile used for injection moulding of all materials was 150, 165, 180, 180 and $180^{\circ} \mathrm{C}$ from feed to exit. The mould temperature was set to $35^{\circ} \mathrm{C}$.

\subsection{Tensile Testing}

Tensile testing was performed using an Instron 33R4204 tensile testing machine (Instron, Norwood, MA, USA), equipped with a 5-kN load cell and a 3300 Controller A604-200 control unit (Instron, Norwood, MA, USA). Strain was measured using an Instron 2630-112 extensometer (Instron, Norwood, MA, USA). The tensile testing specimens were made based on ASTM Standard D638-14 Type I [15]. The specimens were conditioned at $23{ }^{\circ} \mathrm{C}$ and a relative humidity of $50 \%$ for at least $48 \mathrm{~h}$ before testing, as described in ASTM Standard D618 Procedure A [16]. The tests were performed at an extension rate of $10 \mathrm{~mm} / \mathrm{min}$. Five replicates of each composition were tested to failure and the unfilled PP samples up to $23 \%$ strain. Stress, strain, Young's modulus and UTS were calculated by the tensile testing software that was used (Instron Bluehill 3, Instron, Norwood, MA, USA)).

\subsection{Moisture Absorption}

Moisture absorption tests were conducted at 23 and $60^{\circ} \mathrm{C}$. Tensile testing specimens were dried overnight at $80^{\circ} \mathrm{C}$ and weighed to obtain the dry weight of the samples. The compositions used for the moisture absorption consisted of $30 \mathrm{wt} \%$ composites with normal wood filler and CCA-treated wood filler, both with and without the addition of MAPP. Three replicates of all four compositions were used for testing. The procedure followed was: submerging the samples in water, removing the samples from 
the water after a period of time, removing exterior moisture with a paper towel, weighing the samples and submerging the samples again. This procedure was performed multiple times over a period of ten days. The tests at $23{ }^{\circ} \mathrm{C}$ were conducted by placing a container filled with water in a temperature controlled room. The tests at $60^{\circ} \mathrm{C}$ were conducted using a water bath set to that temperature.

\subsection{Scanning Electron Microscopy}

Scanning Electron Microscopy (SEM) was conducted on samples of digested wood and on the fracture surfaces of tensile testing specimens, using a Hitachi S-4700 FE-SEM (Hitachi High-Technologies, Tokyo, Japan). In order to do the microscopy, small amounts of wood chips or fibre were attached to aluminium stubs with carbon tape and sputter coated with platinum. The length of the tensile testing specimens was reduced to the desired length. The fracture surfaces were sputter coated with platinum, and the sides of the samples covered in carbon paint. SEM was conducted at an accelerating voltage of $5 \mathrm{kV}$ and an emission current of $10 \mathrm{nA}$. The micrographs taken during the microscopy ranged from a magnification of 200 to approximately 5000, depending on the sample and the area of interest.

\section{Results and Discussion}

The possibility of using CCA-treated wood in WPCs is investigated, and the results are shown in this section. First, the mechanical properties of the CCA-treated wood composites are discussed, followed by the moisture absorption properties.

\subsection{Mechanical Properties}

The mechanical properties of the composites were determined using tensile testing. Figure 1 shows the stress as function of strain for various compositions. This selection of stress-strain curves shows the general shape for the compositions in order to illustrate the change of the curves with composition. Figure 1a shows the stress-strain curves for the composites without MAPP added. These show a clear increase in the Young's modulus with increasing filler level and a clear decrease in ductility with increasing filler level. Figure $1 b$ shows the stress-strain curves for the composites with MAPP added. These also show a clear increase in the Young's modulus with increasing filler level and a clear decrease in ductility with increasing filler level. Additionally, it can be seen that the UTS increases with increasing filler level. The changes in mechanical properties will be explained in this section using additional graphs.

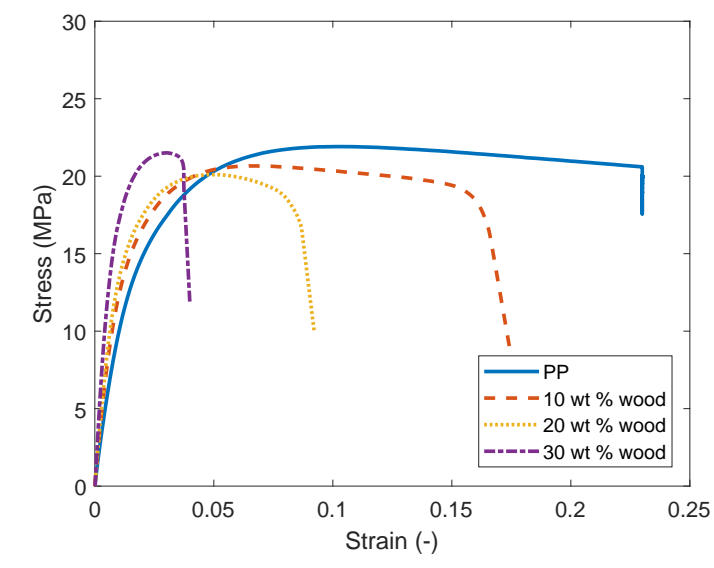

(a)

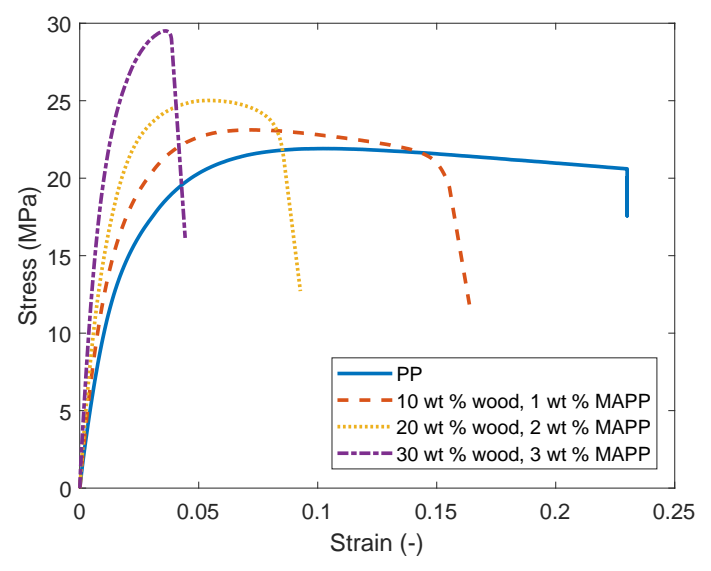

(b)

Figure 1. Selection of typical stress-strain curves for various compositions: (a) without maleic anhydride grafted polypropylene (MAPP); and (b) with MAPP. 
Figure 2 shows the UTS as a function of filler percentage for various compositions. The figure clearly shows two different trends with increasing filler percentage. The first trend shows that the UTS seems to slightly decrease with increasing filler level if there is no MAPP added to the composite. The second trend clearly shows that the UTS increases with increasing filler level for the composites that contain MAPP. These two different trends are caused by the addition of MAPP, which results in a better adhesion between the matrix and the fibre. The increased adhesion can be observed by looking at the fracture surface of tensile specimens. Figure 3 shows scanning electron microscopy (SEM) pictures of the fracture surface of tensile specimens for $30 \mathrm{wt} \%$ CCA filler, with and without MAPP added, at a magnification of 2000 times. Figure 3a shows a fibre that has been pulled out of the matrix. The composite without MAPP added shows this failure mode on the entire fracture surface. Contrarily, Figure $3 \mathrm{~b}$ shows a fibre that has been snapped off. This failure mode can be seen on the fracture surface of the composite with MAPP added; nevertheless, there are still fibres present that have undergone pullout. This difference in failure modes of the fibres shows that the adhesion between matrix and fibres is better when MAPP is added to the composite. This increased adhesion can be the reason for the increase in UTS of the composite, because more stress can be transferred from the matrix to the fibre. The amount of MAPP added seems to have no clear effect on the UTS, which is shown in more detail in Figure 4 for $10 \mathrm{wt} \%$ and $20 \mathrm{wt} \%$ filler. An increase in UTS is observed with the addition of MAPP for both filler percentages, regardless of the amount of MAPP added to the composites.

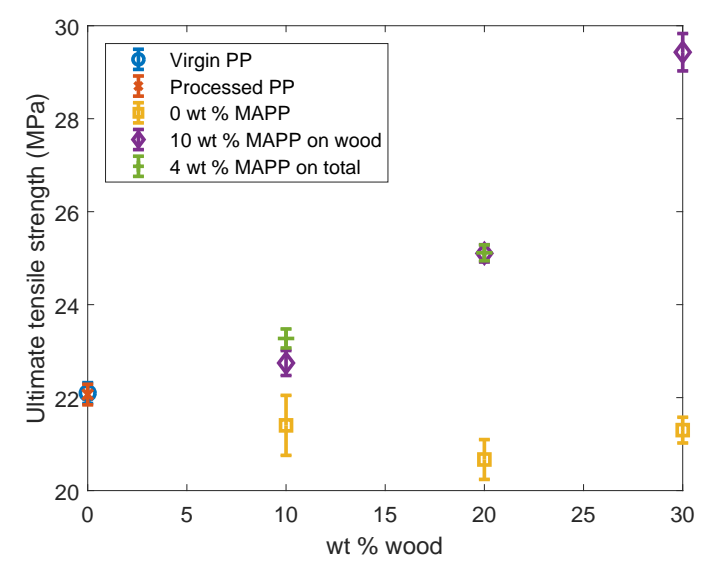

Figure 2. Ultimate tensile strength as a function of filler percentage for various compositions.

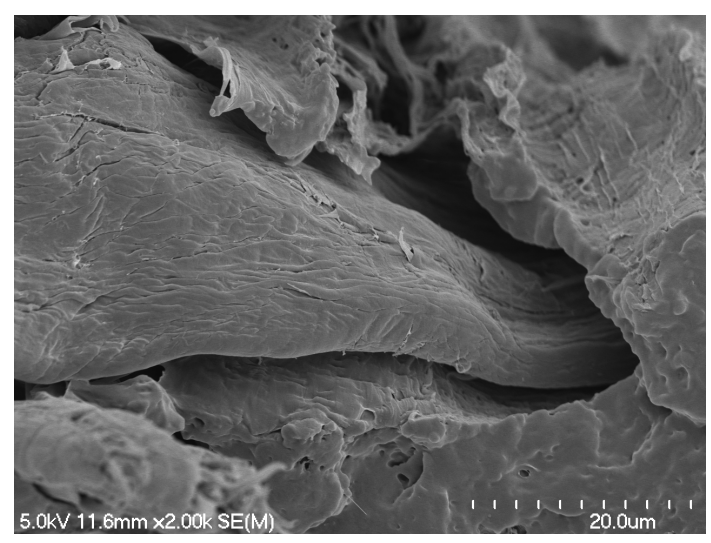

(a)

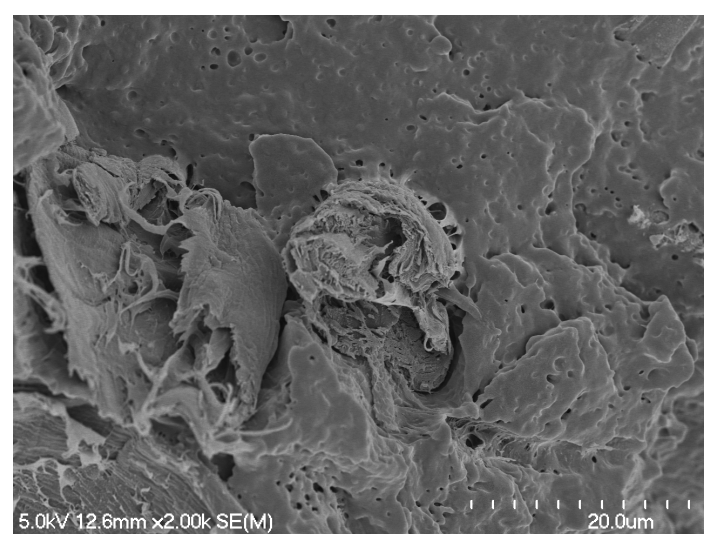

(b)

Figure 3. Scanning electron micrographs of the fracture surface of (a) a tensile specimen with $30 \mathrm{wt} \%$ CCA-treated wood fibres and (b) a tensile specimen with $30 \mathrm{wt} \%$ CCA filler and $3 \mathrm{wt} \%$ MAPP. 


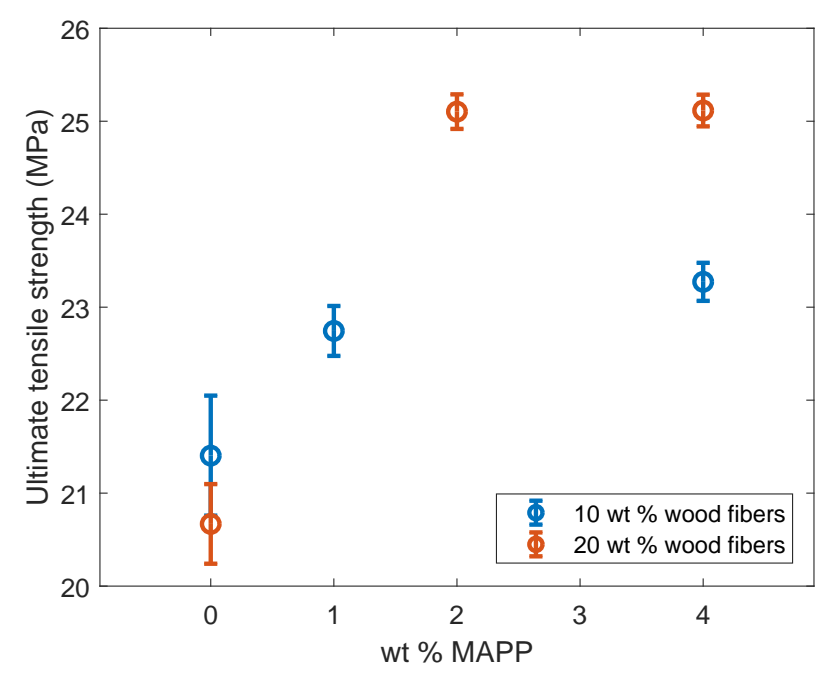

Figure 4. Ultimate tensile strength as function of MAPP percentage for $10 \mathrm{wt} \%$ wood fibres and $20 \mathrm{wt} \%$ wood fibres.

The Young's modulus as function of filler percentage for various compositions is shown in Figure 5. This figure shows that the Young's modulus increases with increasing filler percentage for all compositions; both with and without the addition of MAPP. The increase in the Young's modulus is caused by the addition of rigid particles in the matrix. These particles increase the stiffness, and the more particles are added, the more stiffness is gained, in general, up to a certain filler level. Therefore, the Young's modulus increases with increasing filler level, for these composites up to $30 \mathrm{wt} \%$ filler. Figure 6 shows the Young's modulus for $10 \mathrm{wt} \%$ and $20 \mathrm{wt} \%$ filler. From these figures, it can be seen that the Young's modulus does not increase significantly with the addition of 1 or $2 \mathrm{wt} \%$ MAPP; however, the Young's modulus does increase by more than $30 \%$ with the addition of $4 \mathrm{wt} \%$ MAPP.

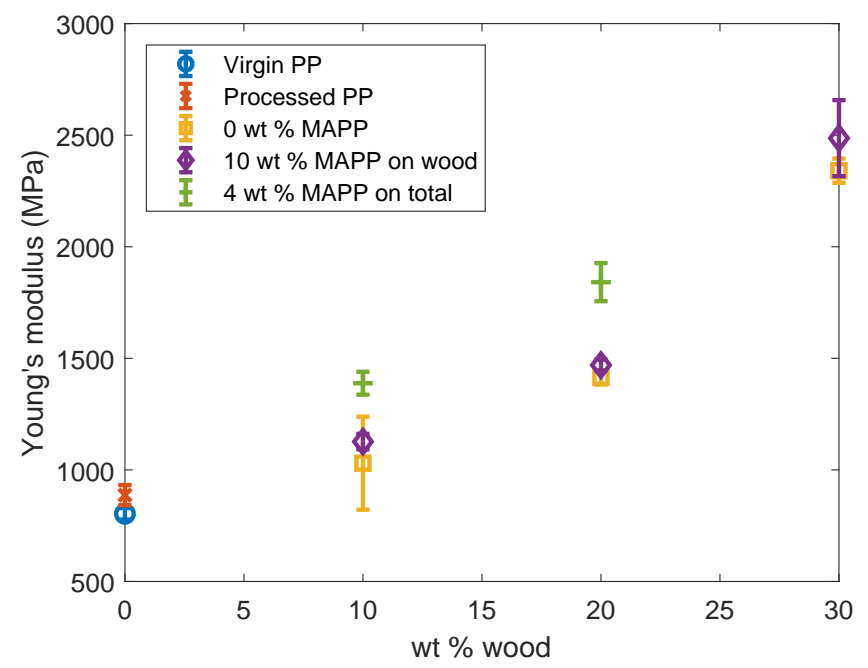

Figure 5. Young's modulus as a function of filler percentage for various compositions. 


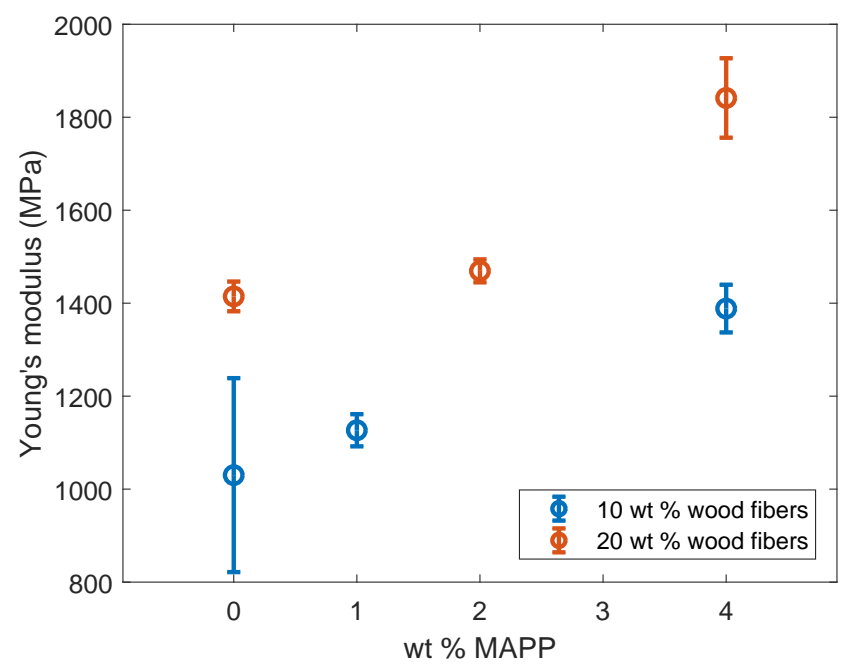

Figure 6. Young's modulus as function of MAPP percentage for $10 \mathrm{wt} \%$ wood fibres and $20 \mathrm{wt} \%$ wood fibres.

The failure strain as a function of filler percentage is shown in Figure 7 for various compositions. The virgin PP was tested up to a strain of $23 \%$; therefore, no failure strain is shown for this material. The figure shows that the failure strain decreases when the filler percentage is increased. This corresponds to the decrease in ductility that can be seen in the stress-strain curves in Figure 1. There is no distinct difference in failure strain between the composites with and without MAPP.

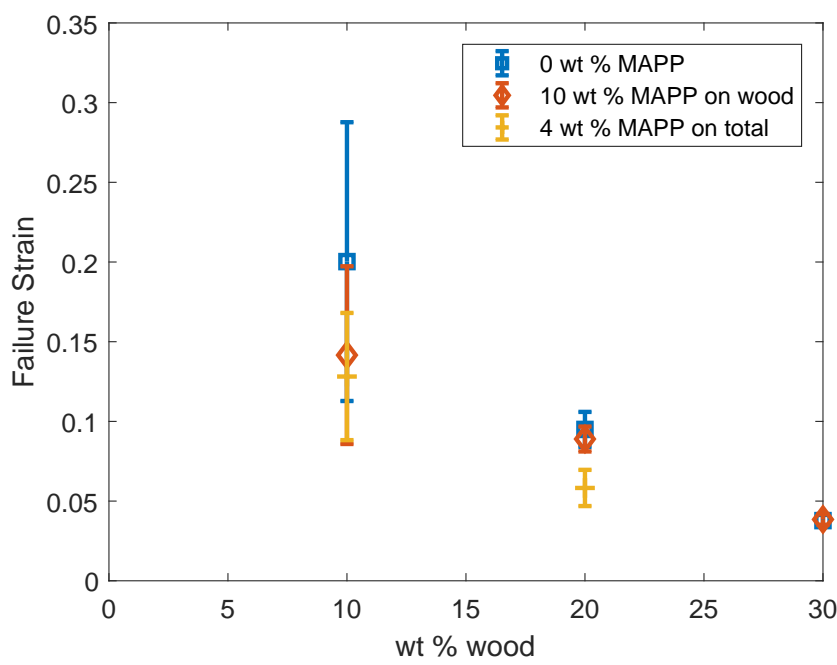

Figure 7. Failure strain as a function of filler percentage for various compositions.

\subsection{Moisture Absorption}

To investigate if the CCA-treated wood filler has additional properties in the form of moisture resistance, moisture absorption experiments were conducted. The CCA treatment of the wood is expected to decrease the hydrophilic character of the wood. Therefore, it might be expected that the moisture absorption of composites, with this filler, is lower than that of composites with virgin wood filler. To be able to compare the composites with CCA-treated and virgin wood filler, the wood is acquired from the same lumber supply store and processed in the same manner. Additionally, the effect of adding MAPP as a coupling agent to the composite is investigated for both virgin wood 
and CCA-treated wood filler. The measure for moisture absorption used is the weight increase of the samples. The percentage of weight increase is calculated using:

$$
\text { increase in weight }=\frac{\text { wet weight }- \text { conditioned weight }}{\text { conditioned weight }} \cdot 100 \%
$$

in which the conditioned weight is the weight of the dry sample before immersion and the wet weight is the weight of the sample measured after immersion [17].

Figure 8 shows the increase in weight as a function of the square root of immersion time for the specimens immersed at $23{ }^{\circ} \mathrm{C}$. The figure shows an increase in weight for all compositions. The difference between the compositions with and without MAPP can be seen clearly from the moment of immersion. The composites with MAPP added have a lower increase of weight than the composites without MAPP. The difference between the CCA-treated wood filler and the virgin wood filler is less pronounced, but is visible in the figure at higher immersion times. In the composites without MAPP added, the figure shows a distinct difference between the weight increase of CCA and virgin wood filler. The composites with CCA-treated wood filler seem to absorb less water. This difference in water absorption is less pronounced in the composites with MAPP added; nevertheless, a slight difference in the increase of weight can be observed.

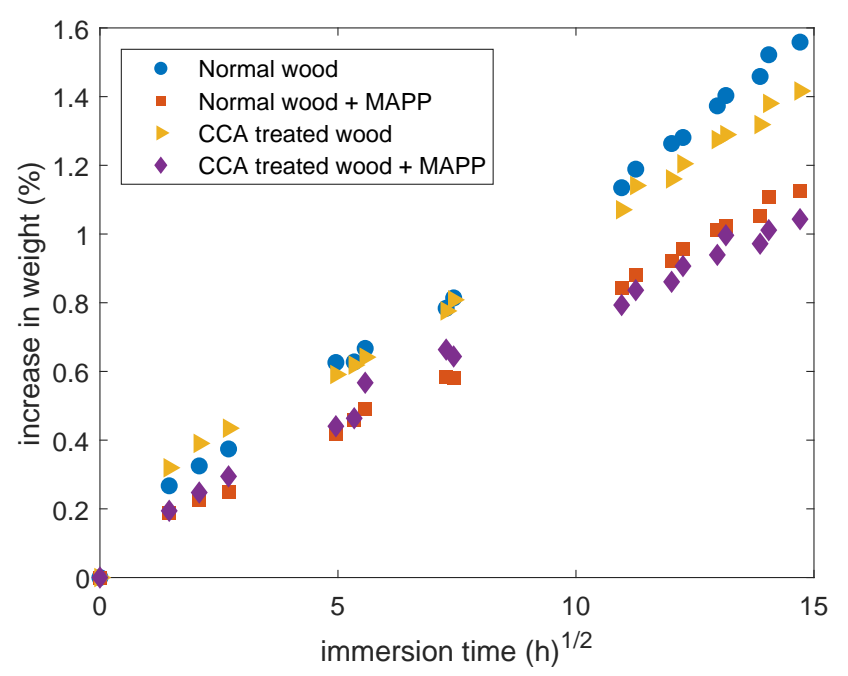

Figure 8. Increase in weight as a function of immersion time at $23^{\circ} \mathrm{C}$.

Figure 9 shows the increase in weight as function of the square root of immersion time for the specimens immersed at $60^{\circ} \mathrm{C}$. It can be seen that there is a higher amount of water absorption at $60{ }^{\circ} \mathrm{C}$ than at $23^{\circ} \mathrm{C}$. The trend of a higher moisture uptake for the composites without MAPP can be seen in this figure, as well. For an increase in weight up to $3 \%$, the same trend as in the $23{ }^{\circ} \mathrm{C}$ experiments can be seen. At a higher weight increase, however, the values for the different compositions shift closer together, making the distinction between the composites with and without MAPP less pronounced. Figure 9 also shows the difference between the CCA-treated and the virgin wood filled composites, in which the CCA-treated wood filler absorbs less moisture than the virgin wood filler. However, in contrast to the results at $23{ }^{\circ} \mathrm{C}$, this difference is only observed for the composites without MAPP. The composites with MAPP have a comparable moisture absorption regardless of the filler type used. These observations agree with the results found by Tascioglu et al. [14]. The reduced moisture uptake for composites with MAPP added can be explained by the improved adhesion and dispersion the coupling agent causes. The better adhesion and dispersion reduce the porosity of the composites and interconnection of the filler, which slows the diffusion of moisture in the matrix. 


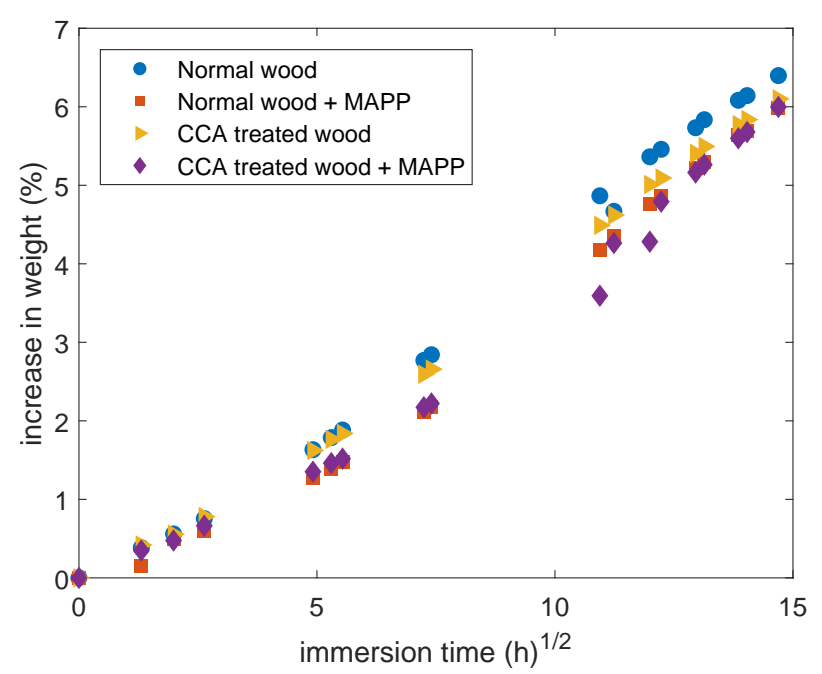

Figure 9. Increase in weight as a function of immersion time at $60^{\circ} \mathrm{C}$.

\section{Conclusions}

This research has shown that it is possible to use chromated copper arsenate (CCA)-treated wood fibres as a filler material in fibre-reinforced composites. If the use of CCA-treated wood in these composites is optimized and applied on a large scale, this could be a possible solution for the disposal of large amounts of CCA-treated wood at the end of its lifetime.

The mechanical properties of the injection moulded polypropylene were affected strongly by the addition of CCA-treated wood filler. For the composites without MAPP, the UTS was shown to decrease slightly with increasing filler percentage. The composites with MAPP showed a strong increase in UTS with increasing filler percentage. Scanning electron microscopy showed that the addition of MAPP improved the adhesion of the fibre to the matrix, resulting in less fibre pullout. The Young's modulus of all compositions increased with increasing filler percentage. The strain at break for the composites decreases strongly with increasing filler percentage. These improvements, in UTS and the Young's modulus, show that CCA wood-filled polypropylene has improved mechanical properties with respect to unfilled polypropylene.

The dimensional stability of the composites was investigated using moisture absorption tests at 23 and $60{ }^{\circ} \mathrm{C}$. These tests show that the composites with the MAPP coupling agent have a lower moisture uptake than composites without MAPP. The CCA additives in the wood filler resulted in a slight decrease in moisture absorption with respect to virgin wood filled composites. However, this decrease in moisture absorption becomes less pronounced at longer immersion times at a higher temperature.

Author Contributions: Conceptualization, W.P. and K.P.; Investigation, W.P.; Supervision, K.P.; Writing, original draft, W.P.; Writing, review and editing, K.P.

Funding: This research received no external funding.

Acknowledgments: The authors would like to thank Jim Bier, Chris Wang and Yuanji Zhang for the assistance in the lab.

Conflicts of Interest: The authors declare no conflict of interest.

\section{References}

1. Holbery, J.; Houston, D. Natural-fibre-reinforced polymer composites in automotive applications. JOM J. Miner. Met. Mater. Soc. 2006, 58, 80-86. [CrossRef]

2. Ashori, A. Wood-plastic composites as promising green-composites for automotive industries! Bioresour. Technol. 2008, 99, 4661-4667. [CrossRef] [PubMed] 
3. Faruk, O.; Bledzki, A.; Fink, H.; Sain, M. Progress report on natural fibre reinforced composites. Macromol. Mater. Eng. 2014, 299, 9-26. [CrossRef]

4. Helsen, L.; Van den Bulck, E. Review of disposal technologies for chromated copper arsenate (CCA) treated wood waste, with detailed analyses of thermochemical conversion processes. Environ. Pollut. 2005, 134, 301-314. [CrossRef] [PubMed]

5. Pickering, K.; Efendy, M.; Le, T. A review of recent developments in natural fibre composites and their mechanical performance. Compos. Part A Appl. Sci. Manuf. 2016, 83, 98-112. [CrossRef]

6. Kalia, S.; Kaith, B.; Kaur, I. Pretreatments of natural fibres and their application as reinforcing material in polymer composites, a review. Polym. Eng. Sci. 2009, 49, 1253-1272. [CrossRef]

7. Kazayawoko, M.; Balatinecz, J.; Matuana, L. Surface modification and adhesion mechanisms in woodfibre-polypropylene composites. J. Mater. Sci. 1999, 34, 6189-6199. [CrossRef]

8. Kuo, P.; Wang, S.; Chen, J.; Hsueh, H.; Tsai, M. Effects of material compositions on the mechanical properties of wood-plastic composites manufactured by injection moulding. Mater. Des. 2009, 30, 3489-3496. [CrossRef]

9. Bledzki, A.; Faruk, O. Wood fibre reinforced polypropylene composites: Effect of fibre geometry and coupling agent on physico-mechanical properties. Appl. Compos. Mater. 2003, 10, 365-379. [CrossRef]

10. Bledzki, A.; Faruk, O. Wood fibre reinforced polypropylene composites: Compression and injection moulding process. Polym. Plast. Technol. Eng. 2004, 43, 871-888. [CrossRef]

11. Stark, N.; Rowlands, R. Effects of wood fibre characteristics on mechanical properties of wood/polypropylene composites. Wood Fiber Sci. 2007, 35, 167-174.

12. Nygård, P.; Tanem, B.; Karlsen, T.; Brachet, P.; Leinsvang, B. Extrusion-based wood fibre-PP composites: Wood powder and pelletized wood fibres-A comparative study. Compos. Sci. Technol. 2008, 68, 3418-3424. [CrossRef]

13. Kamdem, D.; Jiang, H.; Cui, W.; Freed, J.; Matuana, L. Properties of wood plastic composites made of recycled HDPE and wood flour from CCA-treated wood removed from service. Compos. Part A Appl. Sci. Manuf. 2004, 35, 347-355. [CrossRef]

14. Tascioglu, C.; Tufan, M.; Yalcin, M.; Sen, S. Determination of biological performance, dimensional stability, mechanical and thermal properties of wood-plastic composites produced from recycled chromated copper arsenate-treated wood. J. Thermoplast. Compos. Mater. 2016, 29, 1461-1479, doi:10.1177/0892705714565704. [CrossRef]

15. American Society for Testing and Materials. Standard Test Method for Tensile Properties of Plastics; ASTM International: West Conshohocken, PA, USA, 2014.

16. American Society for Testing and Materials. Standard Practice for Conditioning Plastics for Testing; ASTM International: West Conshohocken, PA, USA, 2013.

17. American Society for Testing and Materials. Standard Test Method for Water Absorption of Plastics; ASTM International: West Conshohocken, PA, USA, 2010.

(C) 2018 by the authors. Licensee MDPI, Basel, Switzerland. This article is an open access article distributed under the terms and conditions of the Creative Commons Attribution (CC BY) license (http:/ / creativecommons.org/licenses/by/4.0/). 